OPINION

\title{
Resuscitating an ethical climate in the health system: The role of healthcare workers
}

\author{
P Pillay \\ Dr Prinitha Pillay, BSc (Hons), MB BCh, MSc Infectious Diseases, works for the Rural Health Advocacy Project and has extensive experience \\ working in difficult and remote settings in rural South Africa, and with the humanitarian organisation Médecins Sans Frontières/Doctors Without \\ Borders in Lesotho, Darfur, South Sudan, Sierra Leone, Libya and India.
}

Corresponding author: P Pillay (prinitha@rhap.org.za)

South Africa boasts a proud tradition of healthcare professionals speaking out against injustice in line with the medical doctrine of beneficence (to do good) and maleficence (do no harm). There are many who play a part in making the health system better, including the state, managers, patients and healthcare workers (HCWs). This article looks at the role of HCWs beyond providing medical care to individual patients. HCWs often face a lack of resources enabling them to adequately provide care and treatment and respond to lifethreatening emergencies. As a result, they are forced to make difficult decisions when it comes to allocating those scarce resources. These decisions are not purely fiscal in nature, but also ethical. Deciding who to bump off a theatre list because there is no linen is a choice most HCWs did not imagine they would ever have to make. In order to circumvent a sense of hopelessness, HCWs need to empower and motivate themselves (and others) with knowledge of how to make things better.

S Afr Med J 2015;105(4):277-278. DOI:10.7196/SAMJ.9397

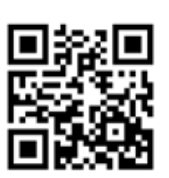

\section{Witnessing the state of} healthcare

Despite steps to improve access to healthcare for all since 1994, South Africa’s healthcare system remains highly inequitable. According to the latest South African Health Review, ${ }^{[1]}$ the $17 \%$ of the population who access private healthcare is served by about $70 \%$ of the country's medical practitioners, $60 \%$ of its specialists and half of its professional nurses. The private sector commands $52 \%$ of the total health budget. The remainder is devoted to serving the majority who use the public sector. The situation is worst in the rural areas. Rural populations carry a double burden - beyond the human resource shortages, they tend to have higher out-of-pocket expenditure accessing public services, such as transport costs when ambulances are not available. ${ }^{[2]}$

As healthcare workers (HCWs), we are confronted with this reality of inequity daily. We are often left deeply frustrated by alltoo-common problems including shortages of medicine, equipment and staff. Many of us work in poorly maintained facilities backed by inadequate budgeting and planning and without access to timely emergency services. It is front-line workers who are often confronted first by the symptoms of an ailing health system struggling to survive.

Perhaps even more worryingly, it has becoming increasingly difficult to speak out about problems like these and violations of patient rights without fear of reprisal. Victimisation, vilification and even death threats in the workplace force HCWs to keep quiet. However, there is a hidden cost of silence and inaction - it can perpetuate the culture of fear and breathes life into the very failure to provide clinical leadership.

There will always be conflicts in healthcare. Within ourselves, we have to uphold the ideals and value system of medicine, and demonstrate this consistently in how we work and live. Externally, conflicts may arise with those to whom we report. HCWs may experience split loyalties, pitting the profession's ethics and duties to patients against those to the state or the employer. However, working within services that impact not only on patients but on their families and communities as well makes the welfare of citizens our primary responsibility.

HCWs are not merely passive employees but active, independent practitioners. When confronted with limited resources and other health system ailments, they have a right to feel frustrated. Indeed, the duty is upon the state to create the enabling conditions for them to deliver the constitutional right to health. Yet, when the state is failing or not making progress fast enough, this does not negate the duty of HCWs to work towards improving the public health system. HCWs respond in different ways to a health system in crisis - some withdraw, others resign, while others continue their patient advocacy, sometimes behind the scenes and sometimes boldly and openly. So what to do if one wants to do good, but not lose hope or one's job?

\section{Making your voice heard}

There is an array of constructive responses at the disposal of HCWs. They should use the available complaint mechanisms as laid out in the National Management of Complaints Protocol (NMCP) at facility, district and provincial levels that have been created for the very purpose of improving the health system. ${ }^{[3]}$ Write and talk to your colleagues, managers, internal clinic or quality improvement committees, or hospital board to advocate for improvements. Start at your facility and escalate to district or provincial level if your concerns haven't been addressed effectively. Familiarise yourself with, and make use of, the Office of Health Standards Compliance and independent bodies such as the South African Human Rights Commission and the Public Protector, as well as independent legal or advocacy organisations.

HCWs need to know that they are entitled to go beyond their manager if they need to, as documented in the NMCP. If workers experience hostility in the workplace, stemming from the reporting of problems in the public interest, they can be protected by the Protected Disclosures Act. ${ }^{[4]}$ Keeping a paper trail, e.g. documenting 
steps taken to resolve problems and responses received, is critical not only in holding those responsible to account but also for personal protection. However, there is power in numbers and HCWs should work together with others and with patients, to amplify their voices.

The challenge is not only to HCWs to empower themselves with this knowledge, but to students who witness healthcare failures, to those who teach and supervise them and to those developing medical curricula, so that all contribute to acting in their patients' interest in an ethical and humanistic manner. ${ }^{[5]}$

There is no getting away from it - it takes hard work to make things work. There is no one-size-fits-all approach to every problem, and the trick is knowing which is the best tool and strategy for a particular context and place. Everyone involved in the health system needs to work continuously and relentlessly in order to create the ethical climate we wish to work within.

Unless we act, and support those who do act, we risk allowing the unacceptable to become acceptable. It is more imperative now than ever before that HCWs remain engaged in monitoring the rights afforded to South Africans by the Constitution, because if we want a different healthcare system, we cannot afford indifference.

'There's really no such thing as the "voiceless". There are only the deliberately silenced and the preferably unheard.' (Arundhati Roy)
This article is a publication of the VOICE Project, co-ordinated by the Rural Health Advocacy Project in partnership with the Rural Doctors Association of South Africa, Rural Rehab Association of South Africa, Professional Association of Clinical Associates in South Africa, Médecins Sans Frontières/Doctors Without Borders, Southern African HIV Clinicians Society and SECTION27. A healthcare provider's guide to reporting healthcare challenges is available at http://rhap.org.za/voiceproject-manual/

1. Padarath A, English R, eds. South African Health Review 2012/2013. Durban: Health Systems Trust, 2013. http://www.hst.org.za/publications/south-african-health-review-2012/13 (accessed 24 February 2015)

2. Harris B, Goudge J, Ataguba JE, et al. Inequities in access to health care in South Africa.J Public Health Policy 2011;32:S102-S123. [http://dx.doi.org/10.1057/jphp.2011.35

3. National Department of Health Office of Standard Compliance Directorate: Quality Assurance. National Complaints Management Protocol for the Public Health Sector of South Africa. Pretoria, 2013. http://www.rhap.org.za/national-complaints-management-protocol-for-the-public-health-sector/ (accessed 24 February 2015)

4. Department of Justice and Constitutional Development. Practical Guidelines for Employees in Terms of Section 10(4)(a) of the Protected Disclosures Act 26 of 2000. Pretoria, 31 August 2011. http://www. justice.gov.za/legislation/notices/2011/20110831_gg34572_n702-disclosure-guidelines.pdf (accessed 24 February 2015).

5. Benatar S. The humanistic side to medical education. S Afr Med J 2015;105(1):3. [http://dx.doi. org/10.7196/SAMJ.9043]

Accepted 2 February 2015. 